\title{
Glucose-6-Phosphate Dehydrogenase Activity and Protein Oxidative Modification in Patients with Type 2 Diabetes Mellitus
}

\author{
Aida A. Mahmoud ${ }^{1}$ and Amal K. A. Nor El-Din ${ }^{2}$ \\ ${ }^{1}$ Biochemistry Department, Faculty of Medicine, Sohag University, Sohag, Egypt \\ ${ }^{2}$ Internal Medicine Department, Faculty of Medicine, Sohag University, Sohag, Egypt \\ Correspondence should be addressed to Aida A. Mahmoud; aidamahmoud11@yahoo.com
}

Received 23 August 2013; Revised 24 October 2013; Accepted 20 November 2013

Academic Editor: Philip Thomas

Copyright (C) 2013 A. A. Mahmoud and A. K. A. Nor El-Din. This is an open access article distributed under the Creative Commons Attribution License, which permits unrestricted use, distribution, and reproduction in any medium, provided the original work is properly cited.

\begin{abstract}
Objectives. The aim of the present investigation was to study the activity of glucose-6-phosphate dehydrogenase (G6PD) and correlate its activity to protein oxidation markers in type 2 diabetic patients under poor glycemic control. Methods. G6PD activity, protein carbonyl group concentration, and total thiol group content were measured in blood samples of 40 patients with type 2 diabetes mellitus under poor glycemic control and 20 healthy control subjects. Results. G6PD activity and total thiol group content decreased significantly while glycated hemoglobin $\left(\mathrm{HbA}_{1 \mathrm{C}}\right)$ and protein carbonyl group concentration increased significantly in diabetic patients than in the controls $(P<0.001)$. In addition, Obtained results revealed that, in diabetics, G6PD activity negatively correlated to protein carbonyl and $\mathrm{HbA}_{1 \mathrm{C}}(r=-0.77$ and -0.65 , resp.), while positively correlated to total thiol $(r=0.66)$ and protein carbonyl negatively correlated to total thiol $(r=-0.85)$, while positively correlated to $\mathrm{HbA}_{1 \mathrm{C}}(r=0.43)$. Also in controls, G6PD activity negatively correlated to protein carbonyl and $\mathrm{HbA}_{1 \mathrm{C}}(r=-0.57$ and -0.56 , resp.), while positively correlated to total thiol $(r=0.5)$ and protein carbonyl negatively correlated to total thiol $(r=-0.48)$, while positively correlated to $\mathrm{HbA}_{1 \mathrm{C}}$ $(r=0.68)$. Conclusions. We concluded that G6PD activity decreased in diabetics than in controls and was negatively correlated to oxidative stress markers and $\mathrm{HbA}_{1 \mathrm{C}}$. G6PD activity can be taken as a biomarker of oxidative stress and poor glycemic control in type 2 diabetic patients.
\end{abstract}

\section{Introduction}

Diabetes mellitus is a metabolic disease characterized by hyperglycemia due to defects in insulin metabolism. If the hyperglyce-mia of diabetes is not managed properly, it causes long-term damage, dysfunction, and failure of different organs, notably the eyes, kidneys, nerves, heart, and blood vessels [1]. An increase in oxidative stress has been observed in diabetic patients, which may be due to an increase in processes that produce oxidants or due to a decrease in the antioxidant defense mechanisms [2].

Glucose-6-phosphate dehydrogenase (EC1.1.1.49; D-Glucose-6-phosphate: $\mathrm{NADP}^{+}$oxidoreductase) is the rate-limiting enzyme of the pentose phosphate pathway. It is required for the antioxidant defense because it produces NADPH, the main cellular reductant and the fuel for glutathione recycling within the cells [3] G6PD plays a central role in cell metabolism and was found to play pathophysiologic roles in many diseases like diabetes, aldosterone-induced endothelial dysfunction, and cancer. The central role of G6PD is being the major source of NADPH, a hydrogen carrier required by many essential cellular systems like glutathione recycling, nitric oxide synthesis, cytochrome p450 system, and others [4]. There is increasing evidence that G6PD activity is of major importance for NADPH production for defense against oxidative stress rather than for ribose production [5]. It was found that hyperglycemia of diabetes mellitus and high glucose levels decrease the activity of G6PD and the inhibition was through the increase in adenylate cyclase activity which in turn increases cAMP levels within the cell [6].

Carbonyl (CO) groups are considered as the most general indicator of protein oxidation. $\mathrm{CO}$ groups (aldehyde and 
TABLE 1: The clinical and laboratory characteristics of the participants.

\begin{tabular}{lcc}
\hline Parameter & Control $(n=20)$ & Diabetics $(n=40)$ \\
\hline Age (years) & $58 \pm 7.1$ & $57 \pm 7$ \\
o/ r ratio & $8: 12$ & $15: 25$ \\
Medications & - & Oral hypoglycemic drugs \\
BMI $\left(\mathrm{kg} / \mathrm{m}^{2}\right)$ & $23.9 \pm 2.1(8.4)$ & $23 \pm 1.7(7.2)$ \\
FBG $(\mathrm{mg} / \mathrm{dL})$ & $101 \pm 10.8(10.7)$ & $274 \pm 50^{* * *}(18.4)$ \\
TC $(\mathrm{mg} / \mathrm{dL})$ & $185 \pm 13(7.1)$ & $238.5 \pm 62.4^{* *}(26.1)$ \\
HDL $(\mathrm{mg} / \mathrm{dL})$ & $39 \pm 3.8(10.1)$ & $30.5 \pm 7.2^{* *}(23.6)$ \\
LDL $(\mathrm{mg} / \mathrm{dL})$ & $183 \pm 13.7(7.5)$ & $229 \pm 40^{*}(17.4)$ \\
Triglyceride $(\mathrm{mg} / \mathrm{dL})$ & $166 \pm 32(19.5)$ & $176.5 \pm 57(32.5)$ \\
HbA $(\%)$ & $5.8 \pm 0.5(8.68)$ & $9.9 \pm 0.96^{* * *}(9.7)$ \\
G6PD activity $(\mathrm{U} / \mathrm{gHb})$ & $8.1 \pm 0.7(8.9)$ & $6.7 \pm 0.76^{* * *}(11.4)$ \\
Protein carbonyl $(\mathrm{nmol} / \mathrm{mg}$ protein) & $3.2 \pm 0.54(16.7)$ & $14.5 \pm 2.14^{* * *}(14.8)$ \\
Total thiol $(\mu \mathrm{mol} / \mathrm{mL})$ & $325 \pm 33(10.3)$ & $201 \pm 18^{* * *}(9.1)$ \\
\hline
\end{tabular}

Data were represented as mean \pm SD (CV \%). FBG: fasting blood glucose; TC: total cholesterol; HDL: high density lipoprotein; LDL: low density lipoprotein; ${ }^{* * *} P<0.001,{ }^{* *} P<0.01,{ }^{*} P<0.05$.

ketones) are produced on protein side chains (especially of Pro., Arg., Lys., and Thr.). When proteins are exposed to oxidants. Protein carbonyl derivatives are also generated when reducing sugars react with lysine residues of proteins with the eventual formation of advanced glycation end products such as pentosidine and carboxymethyllysine [7].

Thiol groups either in free form or bound to proteins play a major role in maintaining the antioxidant status, both intracellularly and extracellularly. Thiols are compounds which contain the sulfhydryl group (-SH) attached to a carbon atom. The reduced thiols found in human plasma are, homocysteine (HcySH), cysteinylglycine (CysGlySH), cysteine (CysSH), and glutathione (GSH) [8]. Albumin exists in both reduced and oxidized forms in systemic circulation and the reduced form of the human serum albumin has been shown to be lower in patients with hepatic disorders, diabetes, and renal diseases. The bulk of free thiol in plasma is represented by Cys-34 of albumin [9]. Thiols help cytoplasm of aerobic cells to maintain a reducing state in the presence of an oxidizing environment [10].

This investigation aimed to study G6PD activity as a biomarker of oxidative stress and correlate its activity to protein oxidation markers; protein carbonyl group concentration and total thiol group content in type 2 diabetes mellitus.

\section{Materials and Methods}

\subsection{Patients and Controls}

Patients. Forty patients (15 $\sigma^{*}$ and 25 \%) with type 2 diabetes mellitus, diagnosed according to the criteria of the Expert Committee [11], were recruited from the department of internal medicine, Sohag University Hospital. Exclusion criteria were, presence of diabetic complications, obesity $(\mathrm{BMI} \geq 30)$, $\mathrm{HbA}_{1 \mathrm{C}}$ less than $7 \%$ and hemolytic disorders. The clinical characteristics of the patients were indicated in Table 1.

Controls. Twenty healthy control subjects, their age and sex distribution were similar to those of the patients. They were subjected to complete medical examination to exclude the presence of medical problems. They were recruited from the hospital staff.

Informed consent was taken from all the participants and all the experiments were strictly adhered to the tenets of the Helsinki declaration.

2.2. Blood Samples. All subjects were advised to take no medication on the morning before blood samples collection. Fasting blood $(5 \mathrm{~mL})$ was obtained from the antecubital vein, after an overnight fasting period (10-12 hours). Samples were divided into two parts: one containing trisodium citrate (final concentration $1 \mathrm{mg} / \mathrm{mL}$ ) for the estimation of G6PD activity. Samples were centrifuged at $1,800 \mathrm{~g}$ for 10 minutes at $4^{\circ} \mathrm{C}$, then, the plasma, buffy coat, and upper $15 \%$ of the packed RBCs were removed and the remaining RBCs were washed twice with PBS and lysed with 9 volumes hypotonic solution ( $5 \mathrm{mM}$ phosphate buffer, $\mathrm{PH} 7.4$ ) on ice. For the estimation of protein carbonyl and total thiol; $3 \mathrm{~mL}$ venous blood was taken into vacutainer clotted tubes and centrifuged at $1,800 \mathrm{~g}$ for 10 minutes and sera were frozen in aliquots and stored at $-20^{\circ} \mathrm{C}$ till time of assay.

2.3. Chemicals. NADP (sodium salt), D-glucose-6-phosphate (monosodium salt), 6-Phosphogluconate (trisodium salt), Guanidine hydrochloride, and 5,5 $5^{\prime}$-Dithiobis (2 Nitrobenzoic acid) were purchased from Sigma (St. Louis, MO, USA), and other chemicals were form MERK (Darmstadt, Germany).

2.4. Methods. Fasting blood glucose, lipid profile and $\mathrm{HbA}_{1 \mathrm{C}}$ were done for all the patients and controls using Cobas $\mathrm{C}$ 311 analyzer, Roche Diagnostics, Germany. G6PD activity assay was performed, using the fresh samples as described by Tian et al. [12]. In this method, the conversion of NADP ${ }^{+}$ to NADPH catalyzed by the two dehydrogenase enzymes in the pentose phosphate pathway was measured by the increase in absorbance at $340 \mathrm{~nm}$ due to the conversion 


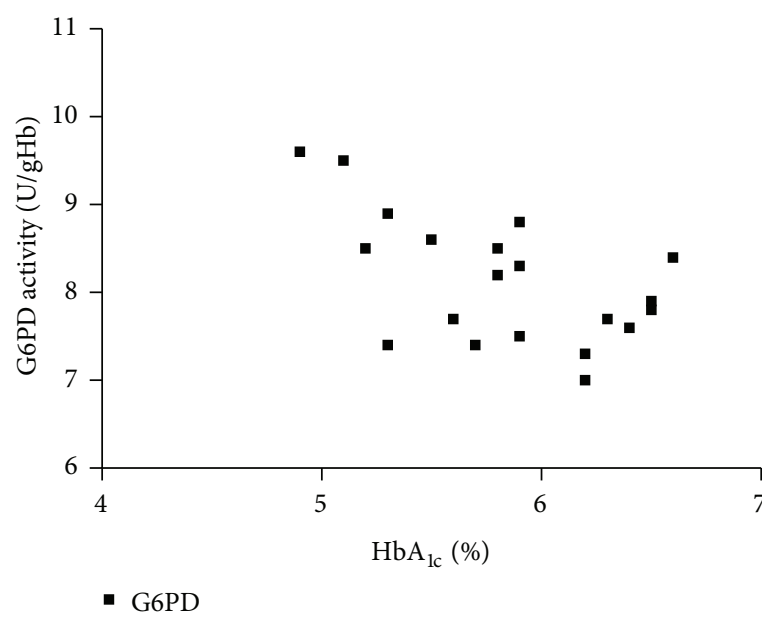

(a)

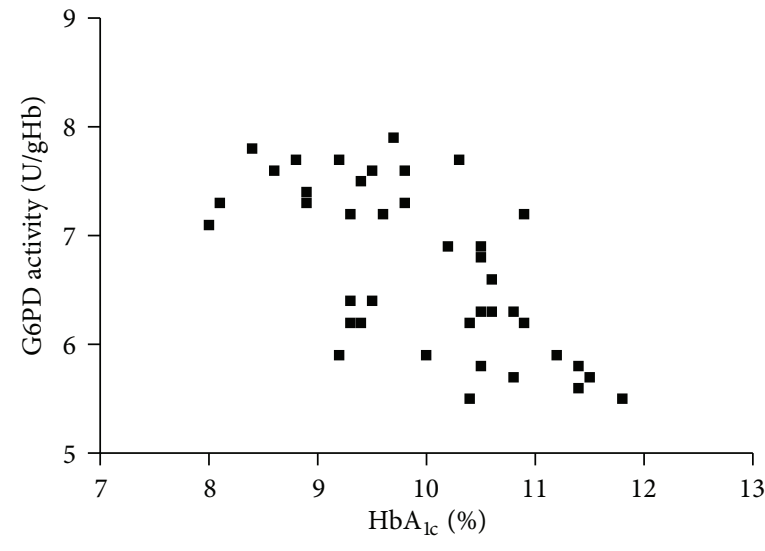

- G6PD

(b)

FIgURE 1: Correlation between $\mathrm{HbA}_{1 \mathrm{C}}$ and G6PD activity in controls (a) and diabetics (b).

of $\mathrm{NADP}^{+}$to NADPH by either G6PD or by the second enzyme 6-phosphogluconate dehydrogenase (6PGD). G6PD catalyzes the conversion of glucose 6-phosphate to 6-phosphogluconolactone, which is rapidly hydrolyzed to 6-phosphogluconate (the substrate for PGD). Thus, to obtain accurate enzyme activities for G6PD and PGD, both PGD activity alone and total dehydrogenase activity (G6PD and PGD) were measured separately. G6PD activity was calculated by subtracting the activity of PGD from total enzyme activity. The unit of enzyme activity is defined as $1 \mu \mathrm{mol}$ of NADPH formed per minute per gram of hemoglobin. Protein carbonyls were measured according to the method of Reznick and Packer [13]. Thiol group was determined based on thiol/disulfide reaction of thiol and Ellman's reagent $\left(5,5^{\prime}\right.$ dithiobisnitrobenzoic acid) [14].

2.5. Statistical Analysis. Data were expressed as mean $\pm \mathrm{SD}$, the coefficient of the variation $(\mathrm{CV} \%)$ of the studied parameters was calculated and data were analyzed using student's $t$-test and Pearson's correlation analysis. $P$-values lower than 0.05 were considered significant. Prism 3 version 5, http://www.Graphpad.com/ was used for analysis.

\section{Results}

The clinical and laboratory characteristics of the participants are represented in Table 1 . Obtained results revealed that G6PD activity and total thiol group decreased significantly in diabetic patients than in the controls $(P<0.001)$, while carbonyl group content increased significantly in diabetics than in controls $(P<0.0001)$. In diabetic patients and controls, G6PD activity negatively correlated to protein carbonyl and $\mathrm{HbA}_{1 \mathrm{C}}$, while positively correlated to total thiol. In addition, protein carbonyl negatively correlated to total thiol, while positively correlated to $\mathrm{HbA}_{1 \mathrm{C}}$ (Table 2), (Figures 1, 2, 3, 4, 5 , and 6 ), indicating the role of poor glycemic control in the development of oxidative stress and diabetic complications.
TABLE 2: Pearsons correlation between the parameters.

\begin{tabular}{lcc}
\hline & Control & Diabetics \\
\hline G6PD activity \& $\mathrm{HbA}_{\mathrm{lc}}$ & $-0.57^{* *}$ & $-0.65^{* * *}$ \\
G6PD activity \& total thiol & $0.5^{*}$ & $0.66^{* * *}$ \\
G6PD activity \& protein carbonyl & $-0.56^{*}$ & $-0.77^{* * *}$ \\
Protein carbonyl \& total thiol & $-0.48^{* *}$ & $-0.85^{* * *}$ \\
Protein carbonyl \& $\mathrm{HbA}_{1 \mathrm{c}}$ & $0.68^{* * *}$ & $0.43^{* *}$ \\
Total thiol \& $\mathrm{HbA}_{\mathrm{lc}}$ & $-0.66^{* *}$ & $-0.29^{*}$ \\
\hline
\end{tabular}

${ }^{* * *} P<0.001,{ }^{* *} P<0.01,{ }^{*} P<0.05$.

\section{Discussion}

In the present investigation, the effects of diabetes mellitus on the activity of G6PD and markers of protein oxidation, protein carbonyl group concentration, and total thiol group content in patients with type 2 diabetes mellitus under poor glycemic were studied. The investigation revealed that the activity of G6PD and total thiol levels decreased significantly in diabetic patients compared to the controls $(P<0.001)$, while protein carbonyl was significantly higher in diabetic patients than in controls $(P<0.001)$. In addition, G6PD activity negatively correlated to protein carbonyl and $\mathrm{HbA}_{1 \mathrm{C}}$, while positively correlated to total thiol and protein carbonyl negatively correlated to total thiol, while positively correlated to $\mathrm{HbA}_{1 \mathrm{C}}$. Hyperglycemia decreases G6PD activity, supported by experimental observations. Zang et al. [15] found that the culture of bovine endothelial aortic cells at highglucose concentration, caused activation of protein kinase A which led to the phosphorylation of G6PD and to a decrease in its activity. The same results were observed in the kidney cortex of diabetic rats and were reversed with insulin treatment [16]. Both posttranslational mechanisms and decreased gene expression appear to be involved in the decrease of G6PD activity that was observed after exposure to high levels of hyperglycemia $(20-30 \mathrm{mmol} / \mathrm{L})$. Recently, it has been shown that high glucose also decreased G6PD 


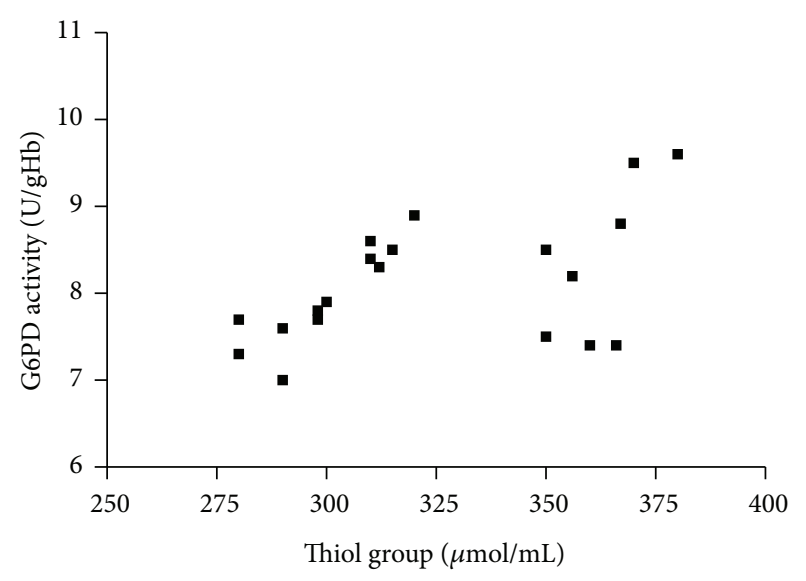

- G6PD

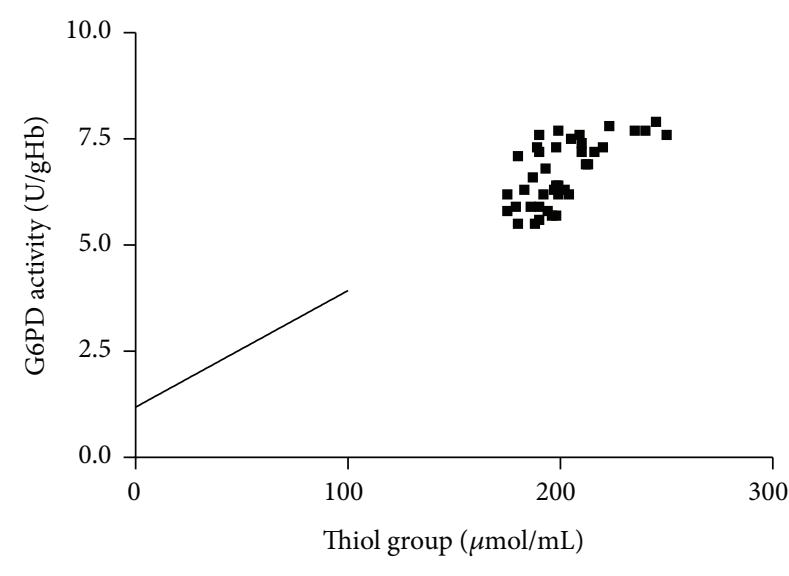

- G6PD

(a)

(b)

FIGURE 2: Correlation between thiol group and G6PD activity in controls (a) and diabetics (b).

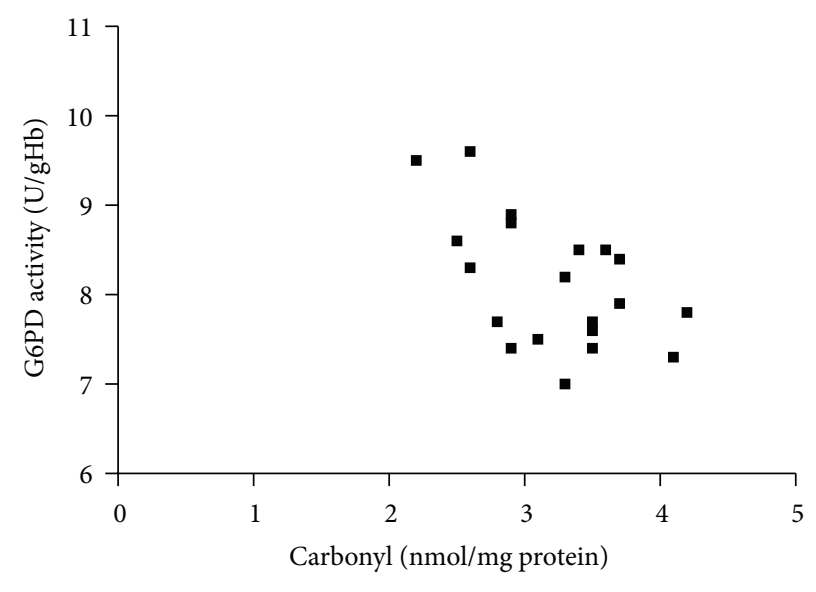

- G6PD

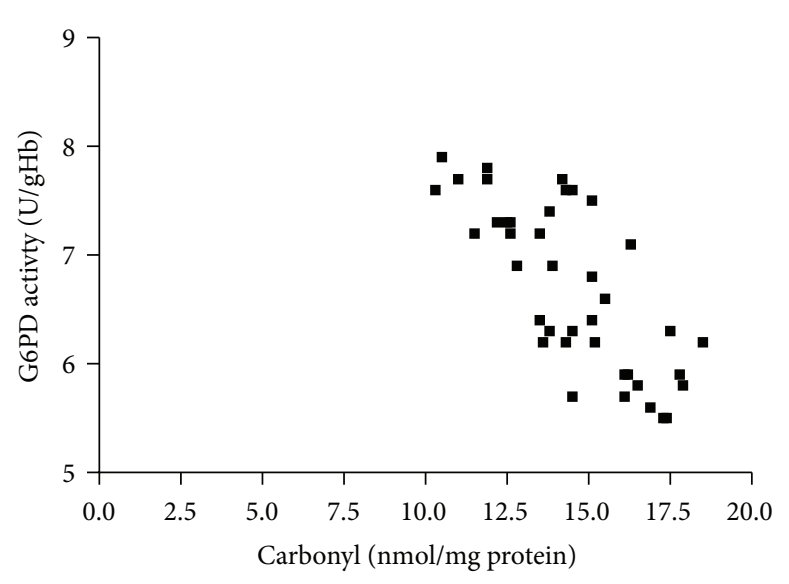

- G6PD

(a)

(b)

FIGURE 3: Correlation between carbonyl group and G6PD in controls (a) and diabetics (b).

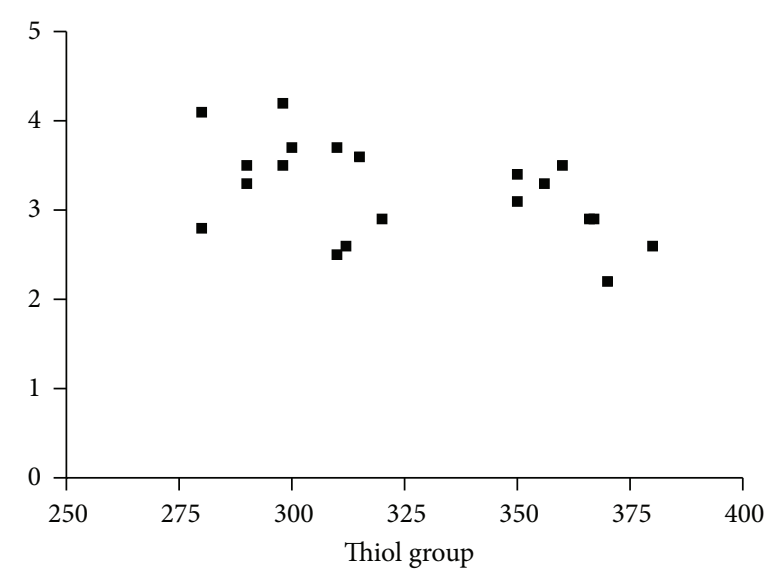

- Carbonyl group

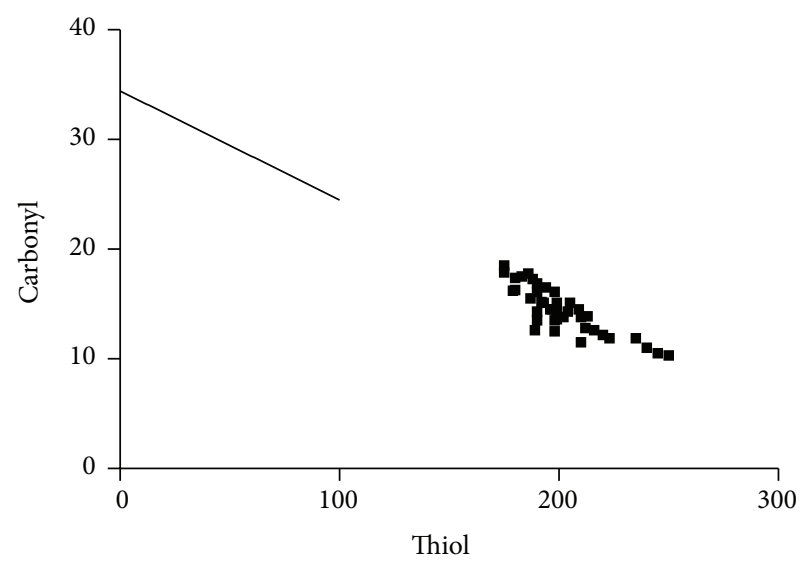

- Carbonyl

(a)

(b)

FIGURE 4: Correlation between carbonyl group and thiol group in controls (a) and diabetics (b). 


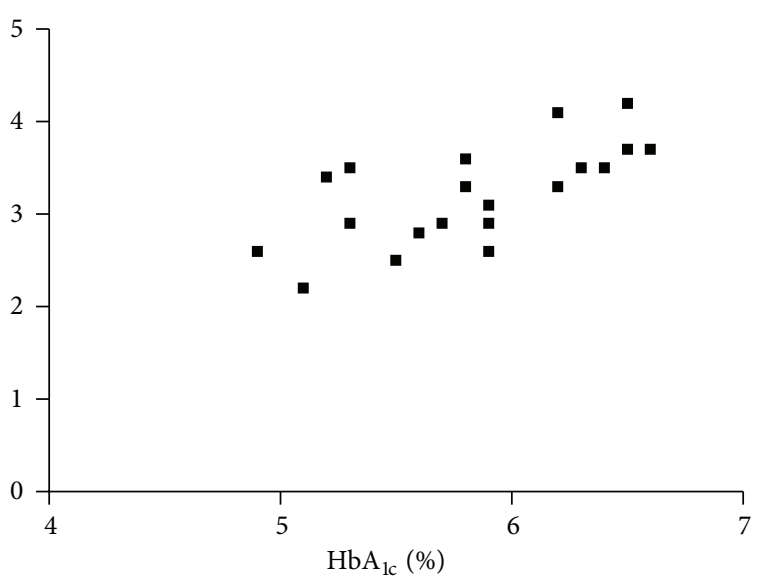

- Carbonyl

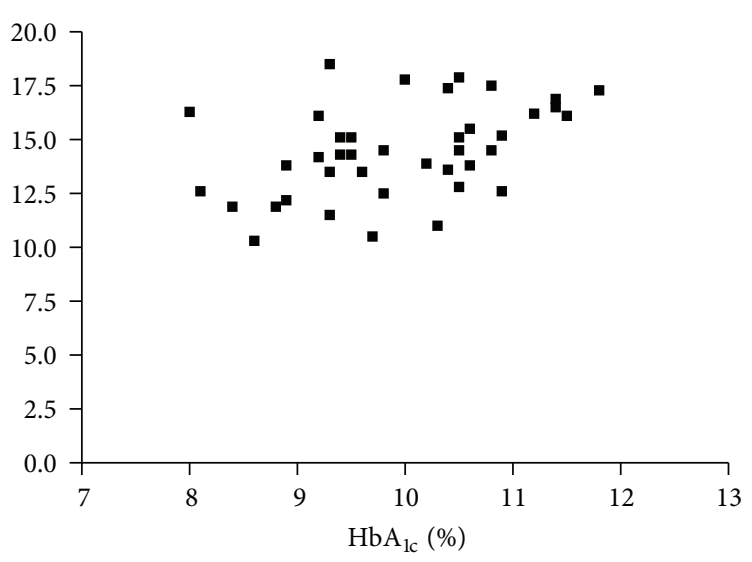

- Carbonyl

(a)

(b)

FIgURE 5: Correlation between $\mathrm{HbA}_{1 \mathrm{C}}$ and carbonyl group in controls (a) and diabetics (b).

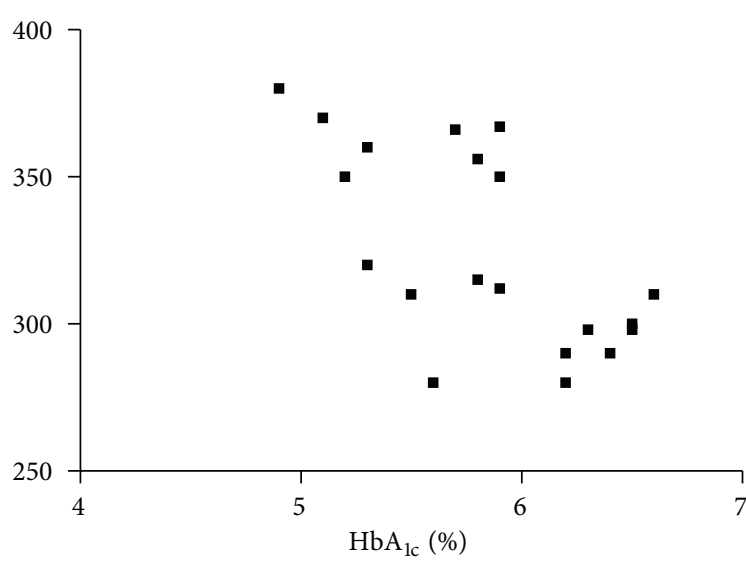

- Thiol

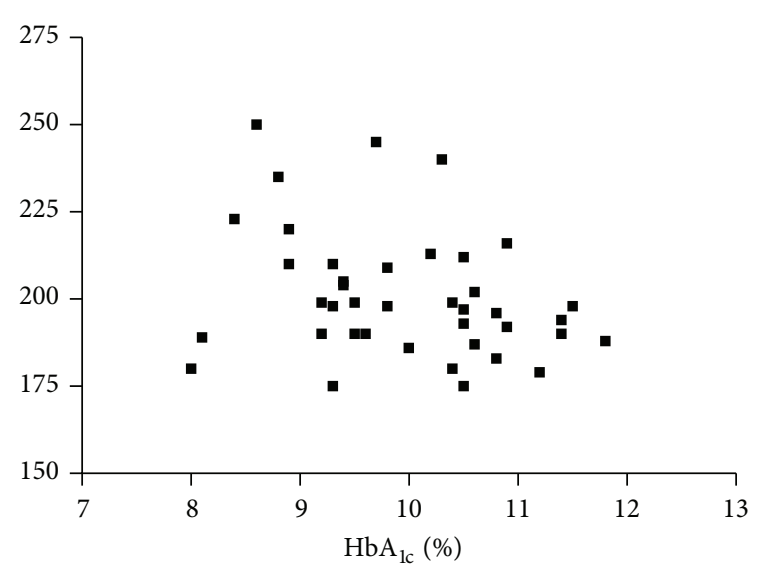

- Thiol

(a)

(b)

FIgURE 6: Correlation between $\mathrm{HbA}_{1 \mathrm{C}}$ and thiol group in controls (a) and diabetics (b).

expression and activity in human islets of pancreas [17]. Hyperglycemia may increase oxidative stress, which affects the normal function of cellular proteins and enzymes. High glucose level was found to activate adenylate cyclase which increases cAMP levels. cAMP activates protein kinase A, an inhibitor of G6PD. G6PD is the major source of NADPH, the main intracellular reductant; hence the decrease in its activity increases the oxidative stress and this was obvious in this investigation through the positive correlation between G6PD activity and protein carbonyl and the negative correlation between G6PD activity and total thiol [18]. In addition, hyperglycemia induces mitochondrial superoxide production which in turn activates four damaging pathways in cells through inhibiting the activity of the key glycolytic enzyme glyceraldehyde-3-phosphate dehydrogenase. Increased levels of glyceraldehyde-3-phosphate activate advanced glycation end product pathway, protein kinase $\mathrm{C}$ pathway, hexosamine pathway, and polyol pathway [19]. It is also found that hyperglycaemia induces effects within the cell nucleus through reactive oxygen species (ROS). Hyperglycaemia initiates a cascade of transcription events, ultimately leading to changes in the levels of NO, cytokines, acute-phase reactants, and cellular adhesion molecules. Generation of ROS can be reduced by avoiding hyperglycaemia and by minimizing fluctuations in blood glucose levels [20].

Several investigators found significant increase in protein carbonyl in diabetic patients [21-24]. The maintenance of protein redox status is essential for cell function, so structural changes in proteins are considered to be among the molecular mechanisms leading to diabetic complications. The introduction of $\mathrm{CO}$ groups into proteins causes alterations in protein conformations leading to increased aggregation, fragmentation, distortion of secondary and tertiary structure, and susceptibility to proteolysis, and decrease of normal function $[25,26]$.

Arif et al. and Çakatay, $[21,22]$ found decreased thiol levels in both type 1 and type 2 diabetes mellitus. The decreases can be due metabolic, inflammatory or iron alterations [27]. 
Free iron in the ferric state was found to be increased significantly in diabetic patients under poor glycemic control and this finding can explain the decrease in protein thiols [28]. Thiols were found as facile targets of glycation and low molecular mass thiols as potent glycation inhibitors. This finding may aid the design of therapeutic agents for the treatment of the complications of diabetes [29]. Uncontrolled hyperglycemia can lead to numerous pathological conditions, eventually resulting in long-term microvascular and macrovascular complications [1]. The antioxidant enzymes usually studied in diabetes include catalase, superoxide dismutase, glutathione system, and thioredoxin system. The novelty of this study was the evaluation of G6PD activity and the correlation of its level to protein oxidation markers. The limitation of this investigation is that a longitudinal study is required, in which measurement of G6PD activity in the same patient takes place in two occasions: under poor glycemic control and after proper management of diabetes to exclude inherited deficiency of the enzyme and emphasize the role of improper management of the disease in the decrease in G6PD activity.

\section{Conclusion}

Improper management of diabetes mellitus caused a decrease in G6PD activity and an increase in protein oxidation markers: protein carbonyl group and total thiol group. G6PD activity can be taken as a biomarker of oxidative stress and poor glycemic control in type 2 diabetes mellitus patients.

\section{Conflict of Interests}

The authors declare that there is no conflict of interests.

\section{References}

[1] American Diabetes Association, "Diagnosis and classification of diabetes mellitus," Diabetes Care, vol. 33, supplement 1, pp. S62-S69, 2010.

[2] T. V. Fiorentino, A. Prioletta, P. Zuo, and F. Folli, "Hyperglycemia-induced oxidative stress and its role in diabetes mellitus related cardiovascular diseases," Current Pharmaceutical Design, vol. 19, no. 32, pp. 5695-5703, 2013.

[3] W. M. Frederiks, K. S. Bosch, J. S. S. G. De Jong, and C. J. F. Van Noorden, "Post-translational regulation of glucose-6phosphate dehydrogenase activity in (pre)neoplastic lesions in rat liver," Journal of Histochemistry \& Cytochemistry, vol. 51, no. 1, pp. 105-112, 2003.

[4] R. C. Stanton, "Glucose-6-phosphate dehydrogenase, NADPH, and cell survival," IUBMB Life, vol. 64, no. 5, pp. 362-369, 2012.

[5] K. Winzer, C. J. F. Van Noorden, and A. Köhler, "Quantitative cytochemical analysis of glucose-6-phosphate dehydrogenase activity in living isolated hepatocytes of European flounder for rapid analysis of xenobiotic effects," Journal of Histochemistry and Cytochemistry, vol. 49, no. 8, pp. 1025-1032, 2001.

[6] Y. Xu, B. W. Osborne, and R. C. Stanton, "Diabetes causes inhibition of glucose-6-phosphate dehydrogenase via activation of PKA, which contributes to oxidative stress in rat kidney cortex," American Journal of Physiology-Renal Physiology, vol. 289, no. 5, pp. F1040-F1047, 2005.
[7] I. Dalle-Donne, D. Giustarini, R. Colombo, R. Rossi, and A. Milzani, "Protein carbonylation in human diseases," Trends in Molecular Medicine, vol. 9, no. 4, pp. 169-176, 2003.

[8] R. Rossi, D. Giustarini, A. Milzani, and I. Dalle-Donne, "Cysteinylation and homocysteinylation of plasma protein thiols during ageing of healthy human beings," Journal of Cellular and Molecular Medicine, vol. 13, no. 9, pp. 3131-3140, 2009.

[9] M. E. Sitar, S. Aydin, and U. Çakatay, "Human serum albumin and its relation with oxidative stress," Clinical Laboratory, vol. 59, no. 9-10, pp. 945-952, 2013.

[10] U. Çakatay, "Pro-oxidant actions of $\alpha$-lipoic acid and dihydrolipoic acid," Medical Hypotheses, vol. 66, no. 1, pp. 110-117, 2006.

[11] Expert Committee on the Diagnosis and Classification of Diabetes Mellitus, "Report of the Expert Committee on the Diagnosis and Classification of Diabetes Mellitus," Diabetes Care, vol. 20, no. 7, pp. 1183-1197, 1997.

[12] W.-N. Tian, L. D. Braunstein, J. Pang et al., "Importance of glucose-6-phosphate dehydrogenase activity for cell growth," The Journal of Biological Chemistry, vol. 273, no. 17, pp. 1060910617, 1998.

[13] A. Z. Reznick and L. Packer, "Oxidative damage to proteins: spectrophotometric method for carbonyl assay," Methods in Enzymology, vol. 233, pp. 357-363, 1994.

[14] M.-L. Hu, "Measurement of protein thiol groups and glutathione in plasma," Methods in Enzymology, vol. 233, pp. 380385, 1994.

[15] Z. Zang, K. Apse, J. Pang, and R. C. Stanton, "High glucose inhibits glucose-6-phosphate dehydrogenase via cAMP in aortic endothelial cells," The Journal of Biological Chemistry, vol. 275, no. 51, pp. 40042-40047, 2000.

[16] Y. Xu, B. W. Osborne, and R. C. Stanton, "Diabetes causes inhibition of glucose-6-phosphate dehydrogenase via activation of PKA, which contributes to oxidative stress in rat kidney cortex," American Journal of Physiology-Renal Physiology, vol. 289, no. 5, pp. F1040-F1047, 2005.

[17] Z. Zhang, C. W. Liew, D. E. Handy et al., "High glucose inhibits glucose-6-phosphate dehydrogenase, leading to increased oxidative stress and $\beta$-cell apoptosis," FASEB Journal, vol. 24, no. 5, pp. 1497-1505, 2010.

[18] Z. Zhang, Z. Yang, B. Zhu et al., "Increasing glucose 6-phosphate dehydrogenase activity restores redox balance in vascular endothelial cells exposed to high glucose," PLoS One, vol. 7, no. 11, Article ID e49128, 2012.

[19] F. Giacco, M. Brownlee, and A. M. Schmidt, "Oxidative stress and diabetic complications," Circulation Research, vol. 107, no. 9, pp. 1058-1070, 2010.

[20] E. Wright Jr., J. L. Scism-Bacon, and L. C. Glass, "Oxidative stress in type 2 diabetes: the role of fasting and postprandial glycaemia," International Journal of Clinical Practice, vol. 60, no. 3, pp. 308-314, 2006.

[21] M. Arif, M. R. Islam, T. M. Z. Waise, F. Hassan, S. I. Mondal, and Y. Kabir, "DNA damage and plasma antioxidant indices in Bangladeshi type 2 diabetic patients," Diabetes \& Metabolism, vol. 36, no. 1, pp. 51-57, 2010.

[22] U. Çakatay, "Protein oxidation parameters in type 2 diabetic patients with good and poor glycaemic control," Diabetes \& Metabolism, vol. 31, no. 6, pp. 551-557, 2005.

[23] E. R. Stadtman and R. L. Levine, "Free radical-mediated oxidation of free amino acids and amino acid residues in proteins," Amino Acids, vol. 25, no. 3-4, pp. 207-218, 2003. 
[24] A. Telci, U. Çakatay, R. Kayali et al., "Oxidative protein damage in plasma of type 2 diabetic patients," Hormone and Metabolic Research, vol. 32, pp. 40-43, 2000.

[25] P. Atukeren, S. Aydin, E. Uslu, M. K. Gumustas, and U. Cakatay, "Redox homeostasis of albumin in relation to alpha-lipoic acid and dihydrolipoic acid," Oxidative Medicine and Cellular Longevity, vol. 3, no. 3, pp. 206-213, 2010.

[26] D. A. Butterfield, T. Koppal, B. Howard et al., "Structural and functional changes in proteins induced by free radical-mediated oxidative stress and protective action of the antioxidants N-tertbutyl- $\alpha$-phenylnitrone and vitamin E," Annals of the New York Academy of Sciences, vol. 854, pp. 448-462, 1998.

[27] A. Van Campenhout, C. Van Campenhout, A. R. Lagrou et al., "Impact of diabetes mellitus on the relationships between iron-, inflammatory- and oxidative stress status," Diabetes/Metabolism Research and Reviews, vol. 22, no. 6, pp. 444-454, 2006.

[28] J. K. Shetty, M. Prakash, and M. S. Ibrahim, "Relationship between free iron and glycated hemoglobin in uncontrolled type 2 diabetes patients associated with complications," Indian Journal of Clinical Biochemistry, vol. 23, no. 1, pp. 67-70, 2008.

[29] J. Zeng and M. J. Davies, "Protein and low molecular mass thiols as targets and inhibitors of glycation reactions," Chemical Research in Toxicology, vol. 19, no. 12, pp. 1668-1676, 2006. 


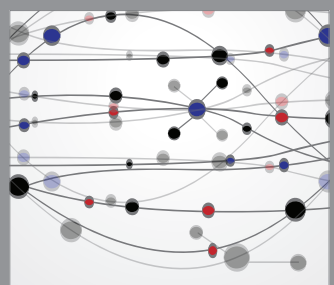

The Scientific World Journal
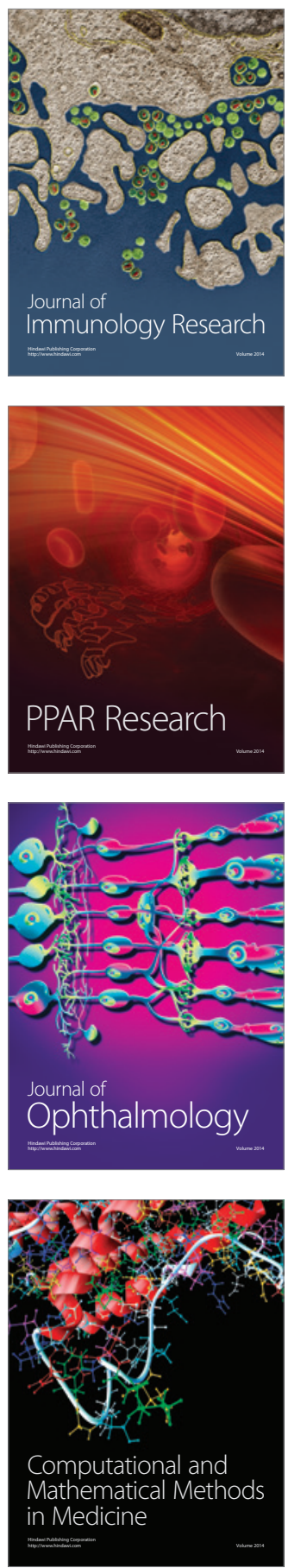

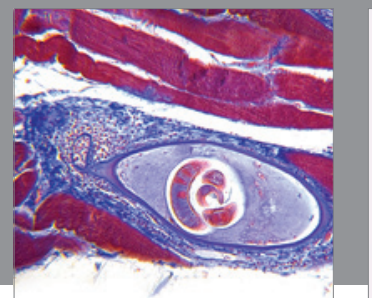

Gastroenterology

Research and Practice
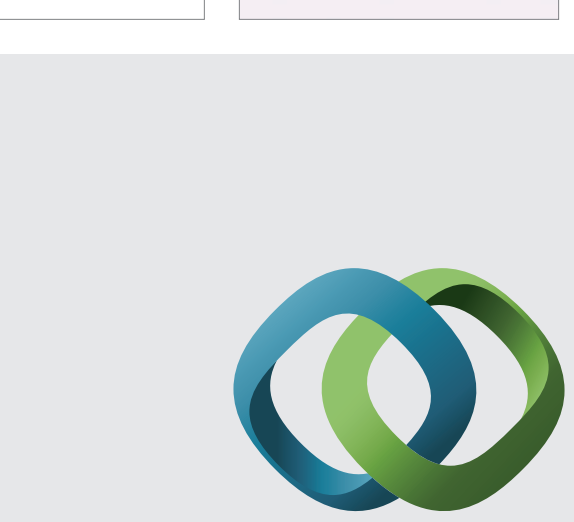

\section{Hindawi}

Submit your manuscripts at

http://www.hindawi.com
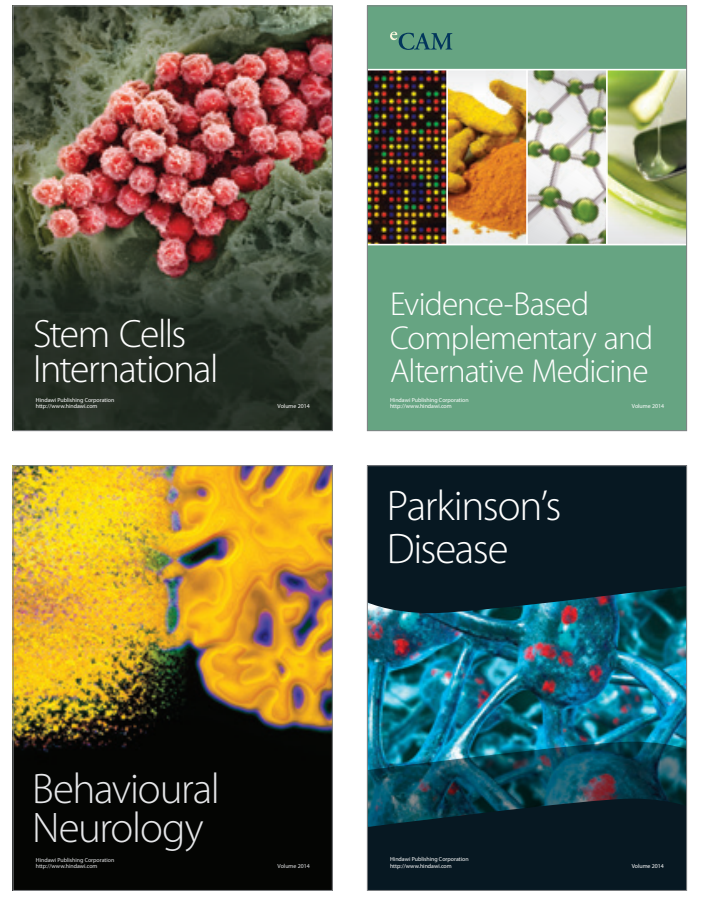
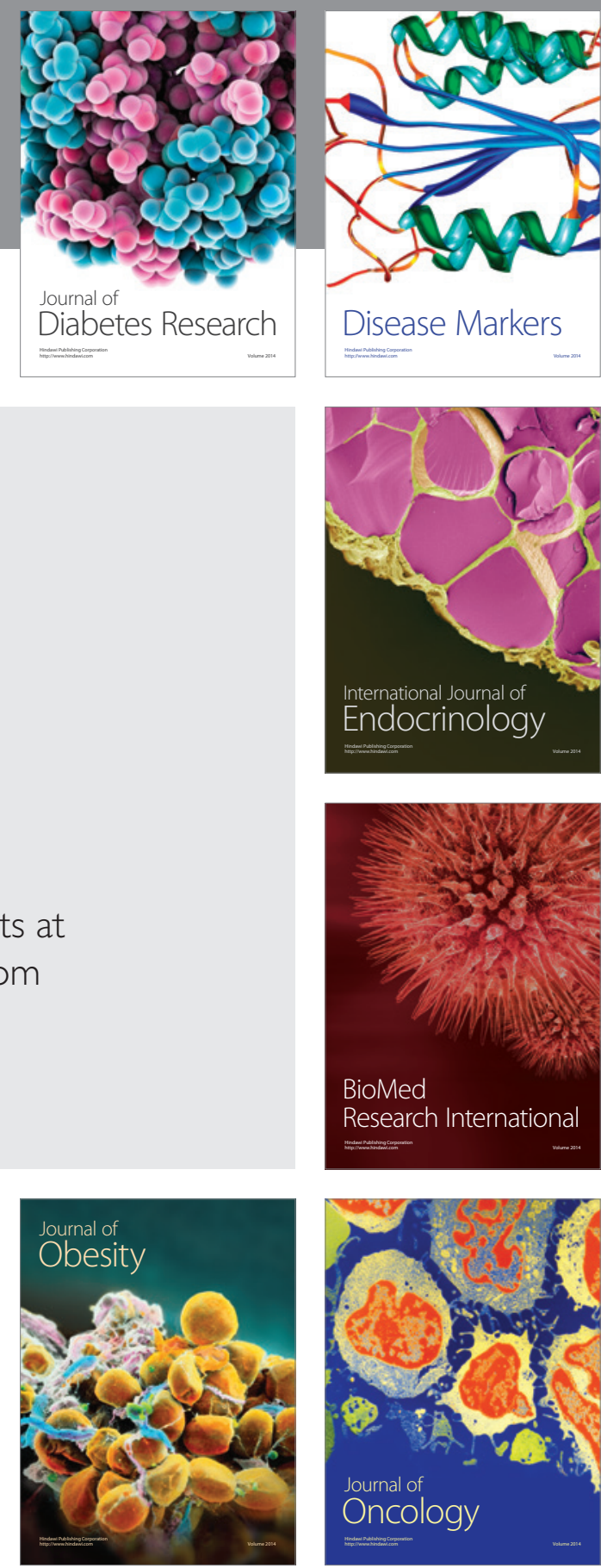

Disease Markers
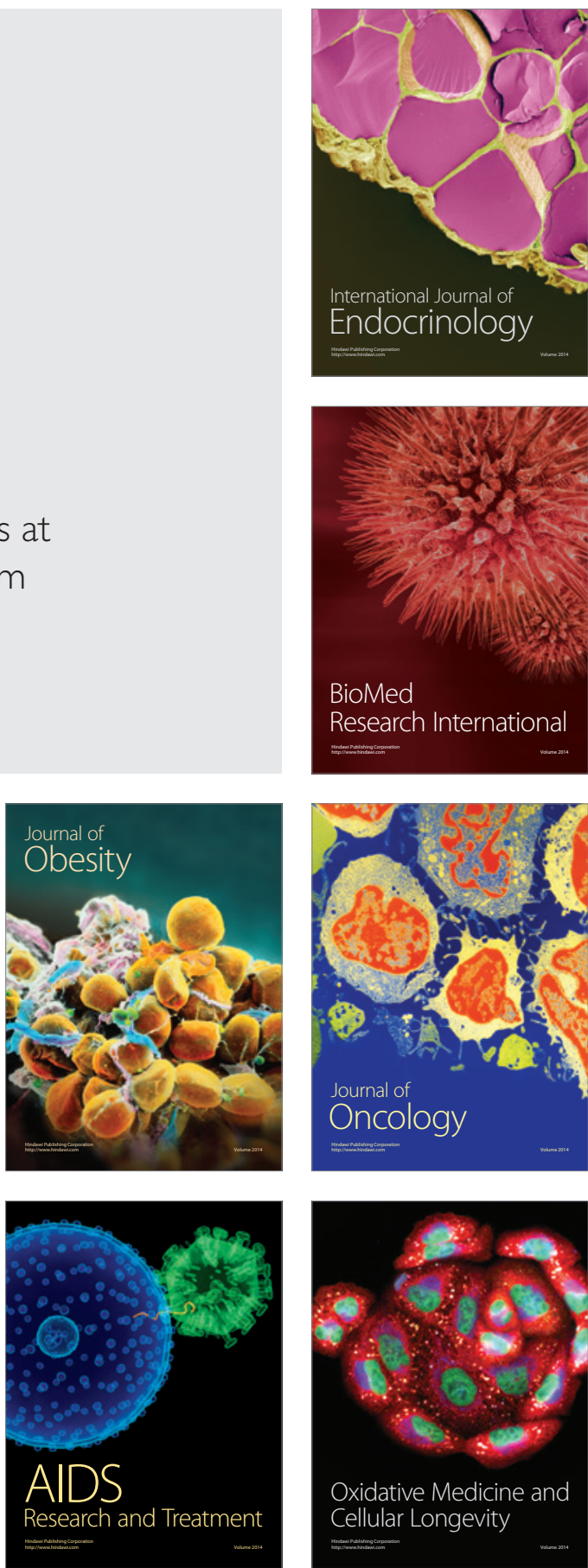